\title{
Prefabrik Düşey Drenlerin Farklı Eşleme Yöntemleri ile Sayısal Analizi
}

\author{
Ufuk TUNÇ*1 ORCID 0000-0002-9986-9456 \\ Hüseyin ÇOLAKOĞLU² ORCID 0000-0001-6804-0963 \\ Erdem ÜSTÜNAY ${ }^{3}$ ORCID $0000-0002-9542-2016$ \\ Abdulazim YILDIZ ${ }^{1}$ ORCID 0000-0002-6755-1902 \\ Baki BAĞRIAÇIK ${ }^{\mathbf{1}}$ ORCID 0000-0002-1860-2881
}

\author{
${ }^{1}$ Çukurova Üniversitesi, Mühendislik Fakültesi, İnşaat Mühendisliği Bölümü, Adana \\ ${ }^{2}$ Adana Alparslan Türkeş Bilim ve Teknoloji Üniversitesi, Mühendislik Fakültesi, İnşaat \\ Mühendisliği Bölümü, Adana \\ ${ }^{3}$ Çukurova Üniversitesi, Rektörlük, Yapı Işsleri ve Teknik Daire Başkanlı̆̆l, Adana
}

Geliş tarihi: 05.07.2021 Kabul tarihi: 10.12 .2021

Atıf şekli/ How to cite: TUNÇ, U., ÇOLAKOĞLU, H., ÜSTÜNAY, E., YILDIZ, A., BAĞRIAÇIK, B., (2021). Prefabrik Düşey Drenlerin Farklı Eşleme Yöntemleri ile Sayısal Analizi. Çukurova Üniversitesi, Mühendislik Fakültesi Dergisi, 36(4), 955-964.

\section{Özet}

Yumuşak zeminler üzerine inşa edilen dolgularda zamana bağlı konsolidasyon oturmalarının dikkatli bir şekilde incelenmesi gereklidir. Bu tür zeminlerde konsolidasyon oturmalarını hızlandırmak için kil zemin içerisine prefabrik düşey drenler inşa edilir. Bu çalışma kapsamında, yumuşak zeminler içine inşa edilen düşey dren sistemlerinin farklı eşleme yöntemleri kullanılarak gerçekleştirilen sayısal analizleri araştırılmıştır. Sayısal analizlerin doğruluğu literatürde yer alan büyük ölçekli konsolidometre deney sonuçları ile karşılaştırılarak kontrol edilmiştir. Deney düzeneği, sonlu elemanlar yöntemine dayanan Plaxis 2D bilgisayar programı ile modellenmiştir. Analizlerde farklı eşleme yöntemleri kullanılarak düşey drenler eksenel simetrik koşullardan düzlem şekil değiştirme koşullara dönüştürülmüştür. Modifiye cam kili modeli kullanılarak gerçekleştirilen analizler deneysel ölçüm sonuçları ile karşılaştırılmış ve aralarında oldukça iyi bir uyum olduğu görülmüştür. Bu sonuçlar, düşey dren sistemlerinin 2 boyutlu koşullarda analiz edilebilmesi için geliştirilen eşleme yöntemlerinin doğru sonuç verdiğini ve bu tür mühendislik uygulamaların analizlerinde tasarım mühendislerine önemli kolaylıklar sağlayacağını göstermiştir.

Anahtar Kelimeler: Büyük ölçekli konsolidometre deneyi, Prefabrik düşey dren, Modifiye cam kili modeli, Sayısal analiz

\footnotetext{
*Sorumlu yazar (Corresponding author): Ufuk TUNÇ, tunc.ufuk@outlook.com
} 


\title{
Numerical Analysis of Prefabricated Vertical Drain with Different Matching Methods
}

\begin{abstract}
Settlement problems arising from civil engineering structures built on soft soils should be carefully examined. There are some soil improvement methods to solve settlement problems on such soils. One of these methods is prefabricated vertical drains (PDD). Vertical drains are used to increase the consolidation speed and shorten the start-up time of the construction. Within the scope of the study, it was planned to compare the results of the laboratory and numerical analysis of vertical drain systems applied in soft soils. The results of large-scale consolidometer experiments conducted in the laboratory were obtained from a study in the literature. A series of analysis were performed for Modified Cam clay (MCC) using different matching methods with the help of the Plaxis 2D computer program based on the finite element method. As a result, it was understood that the analysis results were in a quality supporting the experimental results. For this reason, it is suggested that the matching methods used in such engineering applications will allow practical analysis using the two-dimensional finite element program.
\end{abstract}

Keywords: Large scale consolidometer test, Prefabricate vertical drain, Modify cam clay model, Numerical analysis

\section{GíRiş}

Normal konsolide veya az aşırı konsolide killer geoteknik mühendisliğinde sorunlu zeminler olarak tanımlanır. Bu özellikteki zeminler yumuşak karekterde olup gerek kayma dayanımları gerekse de konsolidasyon oturmaları yönünden önemli mühendislik problemlere neden olabilir. Özellikle yumuşak killerin permeabilitesinin düşük olması ve yüksek sıkışabilirliğe sahip olması nedeniyle konsolidasyon oturmalarının tamamlanması uzun yıllar sürebilir. $\mathrm{Bu}$ durumda boşluk suyu basınçlarının hızlı bir şekilde sönümlenmesini sağlayarak konsolidasyon süresini kısaltmak için kil zemin içerisine düşey drenler inşa edilir. Günümüzde gerek imalat kolaylığı gerekse de ekonomik olması nedeniyle geosentetik malzemeden üretilen prefabrike düşey drenler (PDD) yaygın şekilde kullanılmaktadır.

Dolgular genellikle pratik ve basit olması nedeniyle 2 boyutlu olarak düzlem şekil değiştirime koşullarda analiz edilir. Fakat dolgu altına inşa edilen PDD'ler, eksenel simetrik koşullarda analiz edilmesi gerekir. Bu nedenle dolguların sayısal analizinde PDD’lerin düzlem şekil değiștirme koșullarına dönüștürülmesi gerekir. Hird ve arkadaşları [1], Indraratna and Redana [2], Chai ve arkadaşları [3] eksenel simetrik bir düşey drenin eş değer düzlem şekil değiştirme koşullarına dönüştürülmesi için çeşitli yöntemler geliştirmişlerdir. Bu yöntemlerde, düşey drenler arasındaki aralık ve/veya düşey dren etrafindaki zeminin permeabilitesi ayarlanarak sonlu elemanlar modeli eksenel simetriden düzlem şekil değiştirme koşullarına dönüştürülmektedir.

Saowapakpiboon ve arkadaşları [4] tarafindan gerçekleştirilen çalışmada laboratuvar ortamında büyük ölçekli konsolidasyon düzeneğinde düşey dren davranışını incelemişlerdir. Elde ettikleri deneysel sonuçları, ABAQUS yazılımı ile 2 boyutlu modelleyerek sonuçları karşılaştırmışlardır. Bu çalışmada dolgu altında kil zemin içerisine inşa edilen PDD'lerin farklı eşleme yöntemleri kullanılarak Plaxis 2D yazılımı kullanılarak sayısal analizleri araştırılmıştır. Sayısal analizlerde zemin bünye modeli olarak Modifiye Cam Kili (MCC) modeli kullanılarak hesaplanan oturmalar ölçüm değerleri ile karşılaştırılarak farklı eşleme yöntemlerinin performansı araştırılmıştır. 


\section{MATERYAL VE METOT}

\subsection{Büyük Ölçekli Konsolidasyon Deneyi}

Düşey drenlerin killerde konsolidasyon davranışına etkisini araştırmak için Saowapakpiboon ve arkadaşları [4] tarafından laboratuvar ortamında büyük ölçekli konsolidasyon düzeneği tasarlanmıştır. Böylece arazideki düşey dren davranışı laboratuvar ortamında büyük ölçekli konsolidometre kullanılarak modellenmesi hedeflenmiştir. Deneylerde Bangkok'un yaklaşık $30 \mathrm{~km}$ güneydoğusunda bulunan ikinci Bangkok Uluslararası Havaalanı (SBIA) bölgesinden temin edilen yumuşak karekterdeki kil zemin numuneler kullanılmıştır. Deney düzeneği ve resmi sırasıyla Şekil 1 ve Şekil 2'de gösterilmiştir. Deney düzeneği, iç çapı $0,45 \mathrm{~m}$ ve yüksekliği $0,95 \mathrm{~m}$ olan silindirik bir hücreden oluşmaktadır. Üst ve alt kaideler 40 mm kalınlığında PVC'den yapılmış ve $12 \mathrm{~mm}$ çapında sekiz çelik çubuk ile bağlanmıştır. Piston yükleme sistemi, $40 \mathrm{~mm}$ kalınlığında bir piston ve dış çapı $100 \mathrm{~mm}$ olan içi boş bir şafttan oluşmaktadır. Yükleme pistonunun tıkanmasını önlemek için zemin numunesinin üstüne ve altına geotekstil malzeme yerleştirilmiştir. Deney sırasında boşluk suyu basıncını ölçmek için $200 \mathrm{kPa}$ kapasiteli ölçüm sistemi kil numunenin orta bölgesine farklı derinliklere yerleştirilmiştir. Konsolidasyon sırasında boşluk suyu basınçlarını izlemek için bu ölçüm sistemi bir veri kaydediciye bağlanmıştır [4] (Deney sistemi ile ilgili tüm detaylar için bakınız Saowapakpiboon ve arkadaşları, 2011 [4])

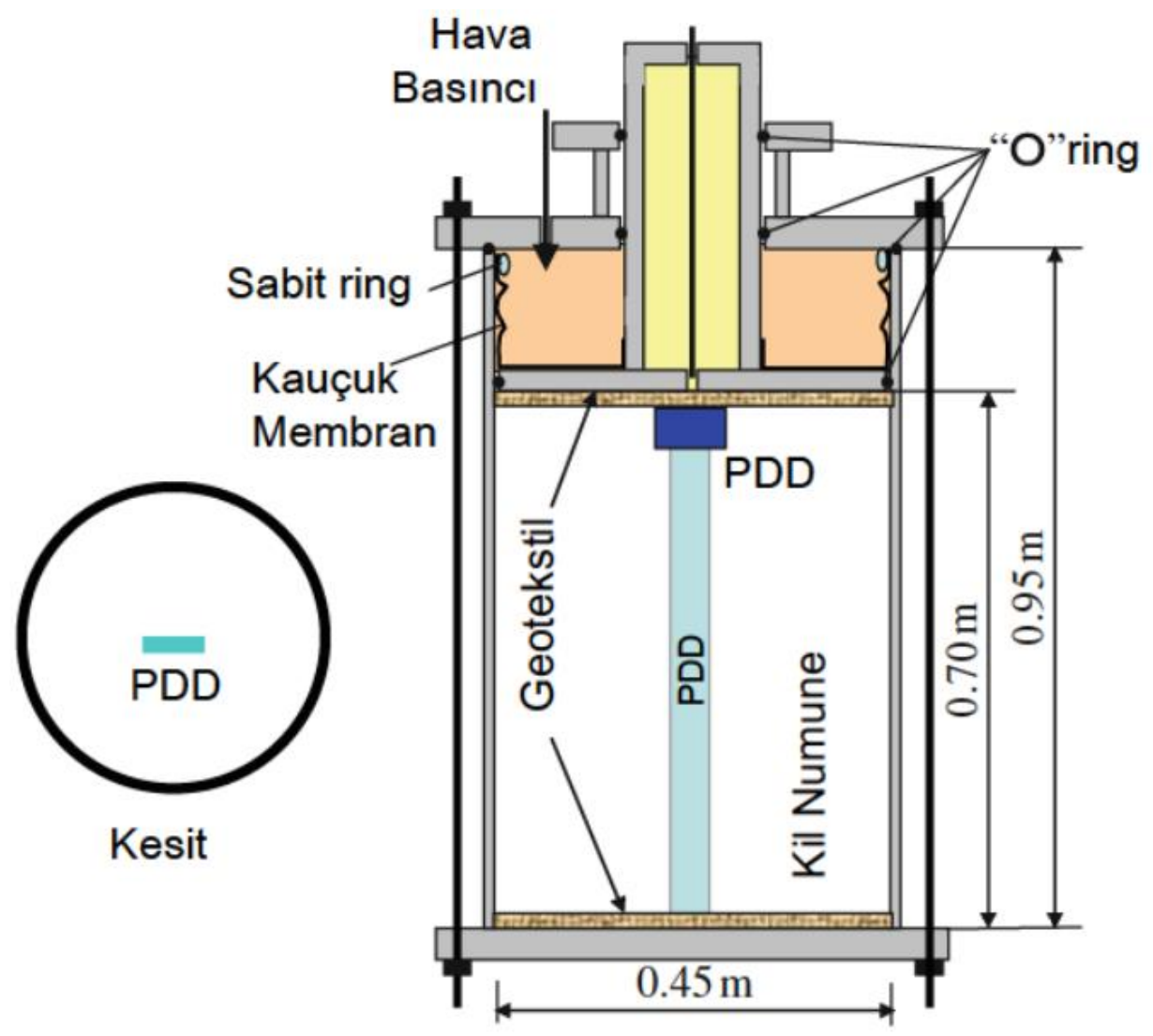

Şekil 1. Büyük ölçekli konsolidometre deney sistemi [4] 


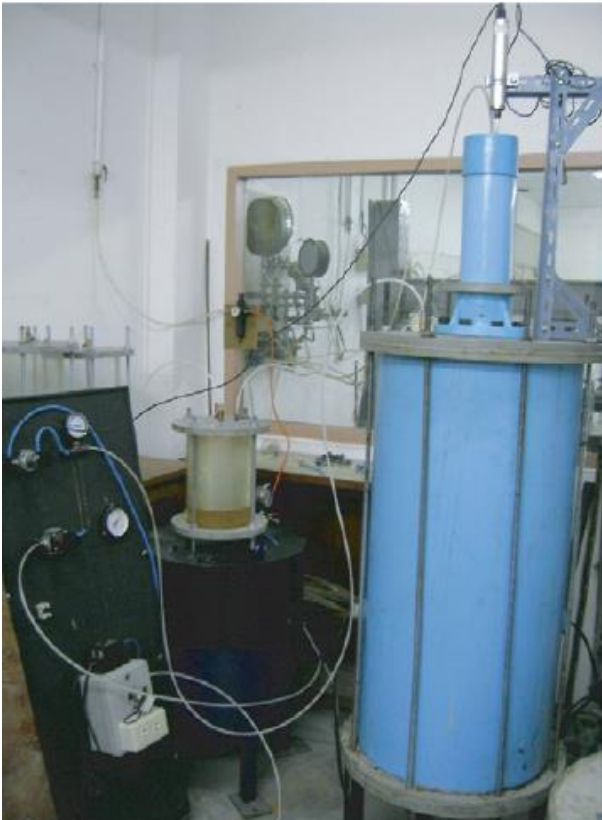

Şekil 2. Büyük ölçekli konsolidometre deney düzeneği [4]

\subsection{Zemin Bünye Modeli}

Sayısal analizlerde yumuşak kil zemin davranışı için kritik durum teorisi çerçevesinde geliştirilmiş olan Modifiye Cam Kili (MCC) modeli kullanılmıştır. MCC modeli, kritik durum teorisi çerçevesinde geliştirilmiş elasto-plastik davranışı esas alan bir zemin bünye modelidir. MCC modelinde kullanılan zemin model parametreleri Çizelge 1'de verilmiştir.

Çizelge 1. MCC model temel parametreleri

\begin{tabular}{|c|c|}
\hline Parametre & Açıklama \\
\hline$\lambda$ & S1kışma indeksi \\
\hline$\kappa$ & Şişme indeksi \\
\hline $\mathrm{e}_{\text {init }}$ & Başlangıç boşluk oranı \\
\hline M & $\begin{array}{c}\text { p'- q üzerindeki kritik durum } \\
\text { çizgisi tanjantı }\end{array}$ \\
\hline $\mathrm{V}_{\mathrm{ur}}$ & Possion oran1 \\
\hline $\mathrm{c}$ & Kohezyon $\left(\mathrm{kN} / \mathrm{m}^{2}\right)$ \\
\hline$\Phi$ & Sürtünme Aç1sı $\left({ }^{\circ}\right)$ \\
\hline$\Psi$ & Dilatasyon Açısı $\left({ }^{\circ}\right)$ \\
\hline $\mathrm{k}_{\mathrm{x}, \mathrm{y}}$ & Permeabilite kaysayısı (m/gün) \\
\hline
\end{tabular}

\subsection{Düşey Drenlerin Sayısal Analizi}

Son yıllarda gelişen bilgisayar teknolojisine paralel olarak geoteknik mühendisliğinde daha gerçekçi çözümler elde edebilmek için sayısal yöntemlerin kullanımı gün geçtikçe yaygınlaşmaktadır [5]. Sonlu elemanlar yöntemi, sayısal analiz yöntemlerinden en sistematik ve en etkin olanıdır. $\mathrm{Bu}$ özelliğiyle sonlu elemanlar yöntemi, farklı malzemelerden oluşan ve karmaşık geometriye sahip geoteknik problemlerin modellenmesine olanak sağlamaktadır. Ayrıca bir eleman için yazılan denklem tüm sistem için kullanılabilir ve bu sayede sürekli bir ortam için ele alınan kısmi difrenasiyel denklem takımına indirgenerek çözülmektedir [6].

Bu çalışmadaki sayısal analizlerde sonlu elemanlar yöntemine dayalı bir yazılım olan PLAXIS (Finite Element Code for Soil and Rock Analysis) [7] paket programı kullanılmıştır. PLAXIS, geoteknik mühendisliğindeki stabilite ve deformasyon problemlerinin analiz edilebimesi için tasarlanmış bir yazılımdır. İlk aşamada laboratuvarda gerçekleştirilen büyük ölçekli konsolidometre deneyi PLAXIS programı ile modellenerek eksenel simetrik koşullarda analiz edilmiştir. Analizlerde zamana bağlı oturmalar MCC modeli ile hesaplanmış ve elde edilen sonuçlar deneysel ölçüm sonuçları ile karşılaştırılarak analizlerin doğruluğu ortaya konmuştur. İkinci aşamada ise silindirik geometriye sahip deney düzeneği ve PDD eleman farklı eşleme yöntemleri ile düzlem deformasyon koşullara dönüştürülerek analiz edilmiştir. Bu analiz sonuçları ölçüm değerleri ile karşılaştırılarak eşleme yöntemlerinin ne kadar güvenilir olduğu araştırılmıştır.

Dolgu altına inşa edilen düşey drenlerin iki boyutlu koşullarda sonlu elemanlar yöntemi ile analiz edilmesi oldukça zordur. Çünkü silindirik geometriye sahip düşey drenlerin düzlem şekil değiştirme koşullara dönüştürülmesi gerekir. $\mathrm{Bu}$ tür problemlerin üç boyutlu analizinin yapılmas1 daha doğru bir yöntemdir. Ancak üç boyutlu analizlerde çok fazla işlem gerektirmesi ve bununla birlikte daha fazla zamana ihtiyaç duyulması nedeniyle bu yaklaşım pratik uygulamalar için çok fazla tercih edilmemektedir. 
Bundan dolayı, düssey drenlerin iki boyutlu analizi yapılırken uygun bir eşleme yöntemi ile düşey drenlerin düzlem şekil değiştirme koşullara dönüştürülmesi gerekir [8].
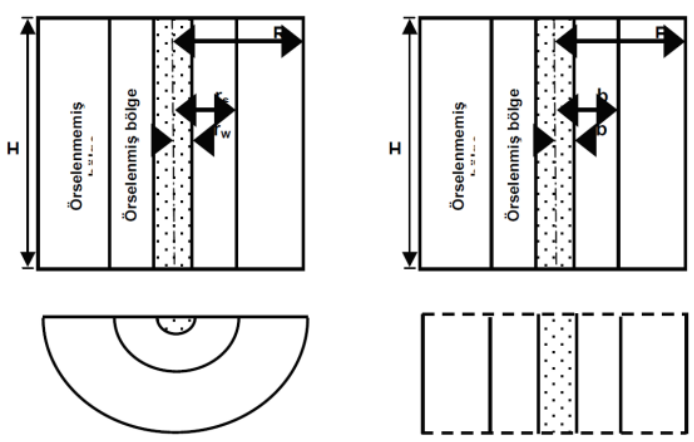

Şekil 3. Birim hücre modeli; eksenel simetrik (solda), düzlem deformasyon (sağda) [8]

Literatürde bu konuda oldukça fazla araştırma bulunmaktadır. Indraratna ve arkadaşları [2] tarafından önerilen eşleme yönteminde düşey drenler için eksenel simetrik geometriden düzlem şekil değiştirme koşullara dönüştürmede model geometrisi korunarak eşleme için permeabilite değerleri kullanılmıştır (Eşitlik 1-2).

$$
\begin{aligned}
& \mathrm{n}=\frac{\mathrm{d}_{\mathrm{e}}}{\mathrm{d}_{\mathrm{s}}} \\
& \frac{\mathrm{k}_{\mathrm{hp}}}{\mathrm{k}_{\mathrm{h}}}=\frac{0,67}{[\ln (\mathrm{n})-0,75]}
\end{aligned}
$$

$\mathrm{Bu}$ bağıntıda $\mathrm{k}_{\mathrm{hp}}$; düzlem şekil değiştirme koşullardaki permeabilite değeri, $\mathrm{k}_{\mathrm{h}}$; zeminin doğal yatay permeabilitesi, $\mathrm{d}_{\mathrm{e}}$; drenin etki bölgesinin çap1 ve $\mathrm{d}_{\mathrm{w}}$; eşdeğer dren çapıdır.

Hird ve arkadaşları [1] tarafindan önerilen eşleme yönteminde birim hücre yöntemi kullanılarak eşleme için permeabilitenin değişmediği kabul edilir ve geometrik uygunluk aşağıdaki bağıntı ile dikkate alınır (Eşitlik 3).

$$
\frac{\mathrm{B}}{\mathrm{R}}=\left\{\left(\frac{3}{2}\right)\left[\ln \left(\frac{\mathrm{R}}{\mathrm{r}_{\mathrm{s}}}\right)+\left(\frac{\mathrm{k}_{\mathrm{h}}}{\mathrm{k}_{\mathrm{s}}}\right) \ln \left(\frac{\mathrm{r}_{\mathrm{s}}}{\mathrm{r}_{\mathrm{w}}}\right)-\frac{3}{4}\right]\right\}^{\frac{1}{2}}
$$

Yukarıdaki bağıntıda, B; düzlem şekil değiştirme koşullarındaki birim hücrenin genişliğinin yarısı, $\mathrm{R}$; eksenel simetrik birim hücrenin yarıçapı, k; zeminin doğal yatay permeabilitesi, $\mathrm{k}_{\mathrm{s}}$; örselenmiş bölgedeki yatay permeabilitesi, $\mathrm{r}_{\mathrm{w}}$ : drenin yarıçapı, $r_{s}$; örselenmiş bölgenin yarıçapıdır.
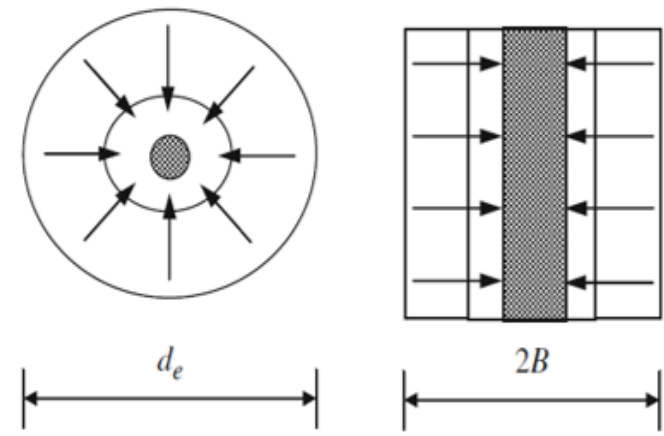

Şekil 4. Birim hücre modeli; eksenel simetrik (solda), düzlem deformasyon (sağda) [2]

Hird ve arkadaşları [1] tarafindan önerilen başka bir yöntem ise, Indraratna ve Redana [2] yöntemine benzer bir yaklaşımla model geometrisi değiştirilmeden eşleme için permeabilite değerleri aşağıdaki bağıntı yardımıyla dönüştürülür (Permeabilite eşleme yöntemi) (Eşitlik 4).

$$
\frac{\mathrm{k}_{\mathrm{pl}}}{\mathrm{k}_{\mathrm{ax}}}=\frac{2}{3\left[\ln \left(\frac{\mathrm{R}}{\mathrm{r}_{\mathrm{s}}}\right)+\left(\frac{\mathrm{k}_{\mathrm{ax}}}{\mathrm{k}_{\mathrm{s}}}\right) \ln \left(\frac{\mathrm{r}_{\mathrm{s}}}{\mathrm{r}_{\mathrm{w}}}\right)-\frac{3}{4}\right]}
$$

Burada $\mathrm{k}_{\mathrm{pl}}$; düzlem şekil değiştirme koşullardaki permeabilite değeri, $\mathrm{k}_{\mathrm{ax}}$; eksenel simetrik koşullardaki permeabilite değeridir.

Chai ve arkadaşları [3] tarafindan ise düşey drenlerin etkisini modellemek için basit bir eşleme yöntemi geliştirilmiştir. Düşey drenler ve zemin davranışı esas alınarak tüm model homojen kompozit bir malzemeye dönüştürülmektedir. Model geometrisi korunarak eşleme için düşey permeabilite değerleri eş değer düzlem şekil değiştirme koşullara aşağıdaki bağıntıyla dönüştürülür (Basit yöntem) (Eşitlik 5 ve 6). 


$$
\begin{aligned}
& \mu=\ln \left(\frac{\mathrm{n}}{\mathrm{s}}\right)+\frac{\mathrm{k}_{\mathrm{h}}}{\mathrm{k}_{\mathrm{s}}} \ln (\mathrm{s})-\frac{3}{4}+\frac{2 \pi \mathrm{l}^{2} \mathrm{k}_{\mathrm{h}}}{3 \mathrm{q}_{\mathrm{w}}} \\
& \mathrm{k}_{\mathrm{ve}}=\left(1+\frac{2,5 \mathrm{l}^{2}}{\mu \mathrm{d}_{\mathrm{e}}^{2}} \frac{\mathrm{k}_{\mathrm{h}}}{\mathrm{k}_{\mathrm{v}}}\right) \mathrm{k}_{\mathrm{v}}
\end{aligned}
$$

Bu bağıntıda, $l$; düşey drenin boyu ve $\mathrm{k}_{\mathrm{ve}}$; eşdeğer düşey permeabilite değeridir. $\mathrm{Bu}$ eşleme yönteminin en önemli kolaylığı dönüşüm yapıldığı takdirde modelde düşey drenleri tanımlamaya gerek duyulmadan düşey drenlerin etkisinin düşey permeabiliteye yansıtılmasıdır.

\subsection{Zemin Özellikleri ve Deney Prosedürleri}

Saowapakpiboon ve arkadaşları [4] tarafindan laboratuvarda gerçekleştirilen büyük ölçekli konsolidometre deneyinde kullanılan yumuşak kil zemine ait endeks özellikler Çizelge 2'de görülmektedir. Konsolidometre deneyinde CeTeau firması tarafindan üretilen CT-D911 modeli PDD malzemesi kullanılmıştır. PDD malzemenin özellikleri Çizelge 3'te özetlenmiştir [4].

Çizelge 2. Yumuşak Bangkok kilinin endeks özellikleri [4]

\begin{tabular}{|l|c|}
\hline Fiziksel Özellik & Değer \\
\hline Likit limit (\%) & 102,24 \\
\hline Plastik limit (\%) & 39,55 \\
\hline Su muhtevası (\%) & 112,69 \\
\hline Plastisite indeksi & 62,69 \\
\hline Birim hacim ağırlığ $\left(\mathrm{kN} / \mathrm{m}^{3}\right)$ & 14,70 \\
\hline Özgül ağırlık & 2,66 \\
\hline
\end{tabular}

Çizelge 3. CeTeau CT-D911 dreninin özellikleri [4]

\begin{tabular}{|c|c|}
\hline A ğırlık $(\mathrm{g} / \mathrm{m})$ & 78 \\
\hline Genişlik, W(mm) & 100 \\
\hline Kalınlık, $\mathrm{t}_{\mathrm{d}}(\mathrm{mm})$ & 3,5 \\
\hline
\end{tabular}

Zemin numuneleri konsolidometreye konulmadan önce sürtünmeyi azaltmak için konsolidometrenin içerisi yağlanmıştır. Daha sonra zemin numuneleri, su içeriği likit limit değerinin üstünde bir su muhtevasında hazırlanmış ve mekanik bir karıştırıcıda iyice karıştırılarak tabakalar halinde konsolidometre içerisine yerleştirilmiştir. Son olarak $50 \mathrm{kPa}$ 'lı bir düşey ilave basınç altında konsolide edilmiştir. Bu esnada konsolidometrede her iki yönde drenaja müsade edilerek Asaoka [9] yöntemine göre konsolidasyon derecesi \%90'lara ulaşana kadar bekletilmiştir. Bu şekilde hazırlanan kil numunelerin kalınlığı yaklaşık $0,7 \mathrm{~m}$ olarak ölçülmüştür [4].

PDD malzeme, $81.9 \mathrm{~mm}$ genişliğinde ve $18.2 \mathrm{~mm}$ kalınlığında bir mini-mandrel (kesit alanı $44 \mathrm{~mm}$ eşdeğer çapa sahip) yardımıyla konsolidemetre içerisindeki kil zemine itilerek yerleştirilmiştir. Ardından konsolidasyon deneyi için zemine düşey yönde $100 \mathrm{kPa}$ konsolidasyon basıncı uygulanarak zamana bağlı oturmalar ölçülmüştür (ilave düşey basınç artışı $50 \mathrm{kPa}$ ). Konsolidasyon deneyi sırasında sadece üst yüzeyde drenaja izin verilmiş olup alt yüzey drenaja kapatılmıştır [4].

Sayısal analizlerde kullanılan MCC zemin model parametreleri laboratuvar deney sonuçlarından belirlenmiş olup Çizelge 4'te listelenmiştir. PDD elemana ait parametreler ise Çizelge 5'te verilmiştir. $\mathrm{Bu}$ tabloda listelenen $\mathrm{d}_{\mathrm{s}}$ değeri, model mandrelin kesit alanının eşdeğer çapının yaklaşık iki katıdır.

Çizelge 4. MCC model parametreleri

\begin{tabular}{|c|c|}
\hline Parametre & Değer \\
\hline$\lambda$ & 0,569 \\
\hline$\kappa$ & 0,052 \\
\hline $\mathrm{e}_{\text {init }}$ & 2,29 \\
\hline $\mathrm{M}$ & 0,8 \\
\hline $\mathrm{vur}_{\mathrm{ur}}$ & 0,3 \\
\hline $\mathrm{c}$ & $1 \mathrm{kN} / \mathrm{m}^{2}$ \\
\hline$\varphi$ & $20,67^{\circ}$ \\
\hline$\Psi$ & $0^{\circ}$ \\
\hline $\mathrm{k}_{\mathrm{x}, \mathrm{y}}$ & $9,0 \times 10^{-5} \mathrm{~m} / \mathrm{gün}$ \\
\hline $\mathrm{K}_{0, \mathrm{nc}}$ & 0,647 \\
\hline
\end{tabular}


Çizege 5. PDD konsolidasyonu için parametreler [4]

\begin{tabular}{|l|c|c|}
\hline Parametre & Sembol & Değer \\
\hline Dren çap1 $(\mathrm{m})$ & $\mathrm{d}_{\mathrm{w}}$ & 0,0268 \\
\hline Örselenmiş bölge çap1 $(\mathrm{m})$ & $\mathrm{d}_{\mathrm{s}}$ & 0,087 \\
\hline $\mathrm{k}_{\mathrm{h}}$ 'nin $\mathrm{k}_{\mathrm{s}}$ 'a oran1 & $\mathrm{k}_{\mathrm{h}} / \mathrm{k}_{\mathrm{s}}$ & 3 \\
\hline $\mathrm{k}_{\mathrm{h}}$ 'nin $\mathrm{k}_{\mathrm{v}}$ 'a oran1 & $\mathrm{k}_{\mathrm{h}} / \mathrm{k}_{\mathrm{v}}$ & 1,5 \\
\hline $\mathrm{k}_{\mathrm{v}}$ 'nin $\mathrm{k}_{\mathrm{s}}$ 'a oran1 & $\mathrm{k}_{\mathrm{h}} / \mathrm{k}_{\mathrm{s}}$ & 3 \\
\hline
\end{tabular}

Sonlu elemanlar yöntemi, sürekli sistemlerin matematiksel olarak tanımlanması ile oluşan bir çözüm yöntemidir. Belirlenen bölgenin eleman adı verilen alt bölgelere ayrılması ve elemanların düğüm noktaları (node) ile ilişkilendirilerek çözüm bölgesi sonlu elemanlar ağına dönüştürmesi, sonlu elemanlar yöntemini diğer sayısal yöntemlerde ayıran en önemli özelliğidir [6]. Bu çalışmada sonlu eleman ağ Plaxis 2D programında Medium Mesh (orta ağ) seçilerek oluşturulmuştur. Plaxis 2D programında, sonlu elemanlar yöntemine göre yapılan analizde ilk aşamada PDD'nin etkisini modellemek için eksenel simetrik koşullarda analizler gerçekleştirilmştir. İkinci aşamda ise deney düzeneği düzlem şekil değiştirme koşullara 3 farklı eşleme yöntemi ile dönüştürülerek analiz edilmiştir. Modelde sınır koşulları, alt sınır yer değiştirmelere iki yönde de izin verilmemektedir $\left(u_{x}=u_{y}=0\right)$. Sağ ve sol kenarlar yatay yer değiştirmelere izin vermemektedir $\left(u_{x}=0\right)$ (Şekil 5.a). Sağ ve alt kenar drenaja kapatılmış ve yer altı su seviyesi alt sınırda tanımlanmıştır (Şekil 5.b).

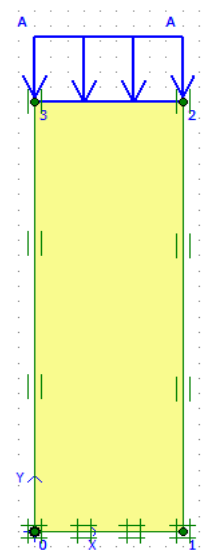

a) Geometrik model

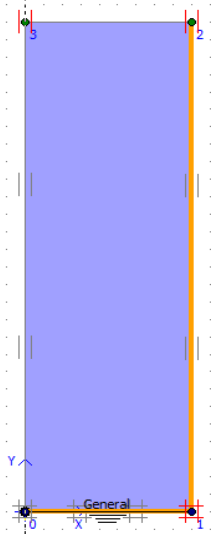

b) Başlangıç koşulları
Sekil 5. Deneyin PLAXIS 2D progamında modellenmesi

\section{BULGULAR VE TARTIŞMA}

Sayısal analizlerde farklı eşleme yöntemleri ile düzlem şekil değiştirme koşullara dönüştürülen düşey drenlerin zamana bağlı davranışı eksenel simetrik analiz ve deney sonuçları ile karşılaştırılmıştır. Analizlerde kil zemin davranışı için elasto-plastik Modifiye Cam Kili (MCC) modeli kullanılmıştır.

İlk aşamada eksenel simetrik geometriye sahip deney düzeneği 2 boyutlu eksenel simetrik koşullarda analiz edilerek deney sonuçları ile karşılaştırılmıştır (Şekil 6).

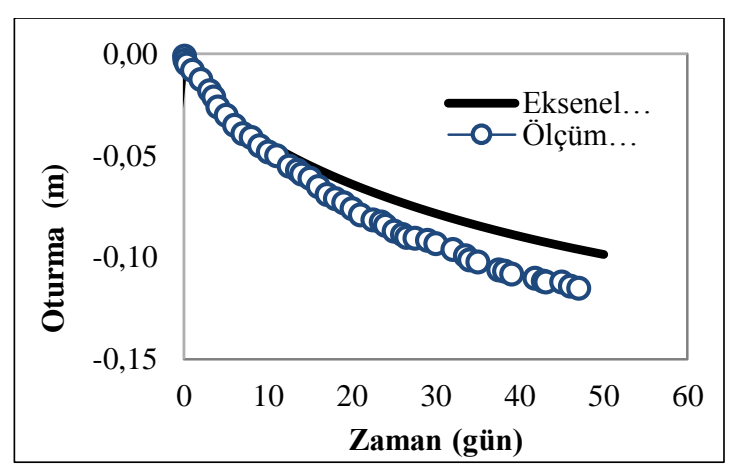

Şekil 6. Deney verileri ile eksenel simetrik analiz sonuçlarının karşılaştırılması

MCC zemin modeli ve eksenel simetrik koşullarda analizde zamana bağlı oturma değeri 50 . günün sonunda $100 \mathrm{~mm}$ olarak elde edilmiştir. Ölçüm sonuçlarında 50. günün sonunda yaklaşı $115 \mathrm{~mm}$ olarak belirlenmiştir. Deney ve analiz sonuçları arasında oldukça iyi bir uyum olduğu görülmektedir. $\mathrm{Bu}$ sonuçlardan düşey drenli yumuşak kilin konsolidasyon davranışının MCC model ile PLAXIS programında başarılı şekilde modellendiği görülmüştür.

Sayısal analizlerin ikinci aşamasında ise eksenel simetrik geometriye sahip deney düzeneği farklı eşleme yöntemleri kullanılarak 2 boyutlu düzlem şekil koşullara dönüştürülmüştür. İlk olarak düşey drenler, Indraratna ve Redana [2] tarafindan önerilen eşleme yöntemine göre düzlem gerilme koşullara dönüştürülmüş ve analiz edilmiştir. Deney verileri ve bu eşleme yöntemi ile elde edilen analiz sonuçları Şekil 7'de karşılaştırılmıştır. 


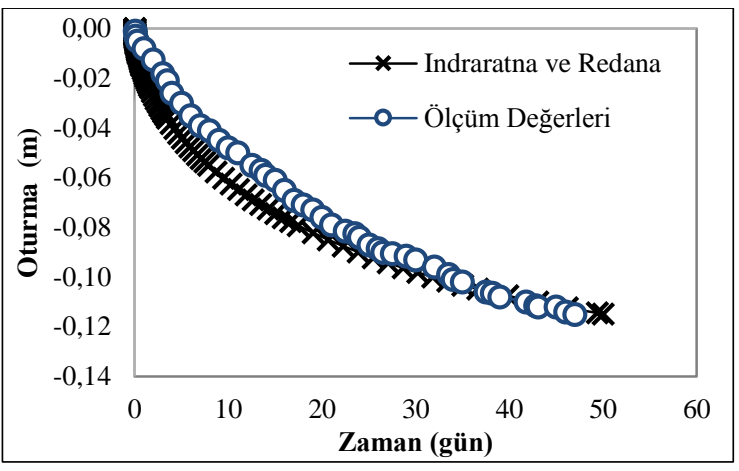

Şekil 7. Indraratna ve Redana eşleme yöntemi analiz sonuçları

Indraratna ve Redana [2] tarafindan önerilen eşleme yöntemi ile 50 . günün sonunda $110 \mathrm{~mm}$ oturma değeri hesaplanmıştır. Deneysel ölçüm sonuçlarına yakınlığı ve uygunluğunun çok iyi olduğu görülmektedir. Daha sonra deney düzeneği Hird ve arkadaşları [1] tarafından önerilen permabilite ve geometri eşleme yöntemleri kullanılarak düzlem deformasyon koşullara dönüştürülmüştür. Şekil 8 ve 9'da Hird ve arkadaşları [1] tarafından önerilen permabilite ve geometri eşleme yöntemleri kullanılarak elde edilen analiz sonuçları görülmektedir. Analiz sonuçlarının deney verileri ile çok iyi bir uyum içerisinde olduğu görülmektedir. Her iki eşleme yöntemi de yaklaşık aynı sonuçları vermektedir. 50. günün sonunda yaklaşık $110 \mathrm{~mm}$ oturma değeri elde edilmiştir. $\mathrm{Bu}$ eşleme yöntemlerinin deney verileri ile olan uyumlarından doğru sonuç verdiği görülmüştür.

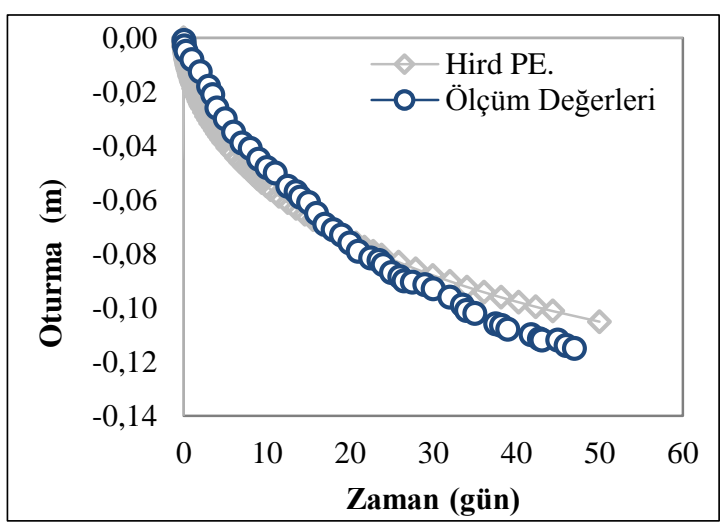

Şekil 8. Hird permabilite eşleme yöntemi analiz sonuçları

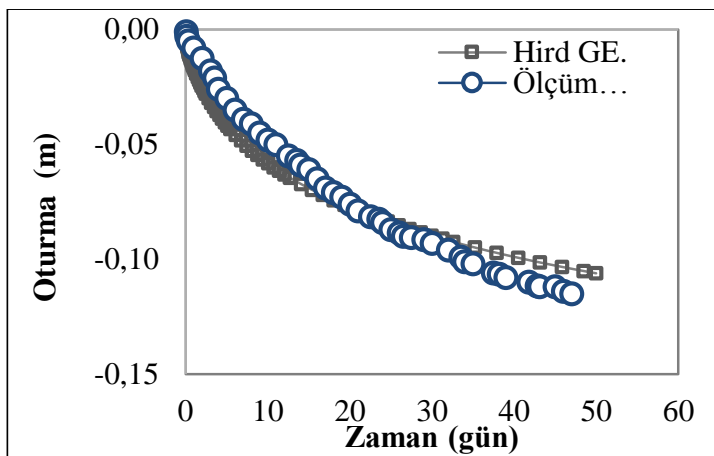

Şekil 9. Hird geometri eşleme yöntemi analiz sonuçları

Son olarak deney düzeneği Chai ve arkadaşları [3] tarafından önerilen eşleme yöntemi (basit yöntem) ile düzlem şekil değiştirme koşullara dönüştürülmüştür. Deney verileri ile analiz sonuçları Şekil 10'da karşılaştırılmıştır. Chai ve arkadaşları [3] (basit yöntem) tarafindan geliştirilen yöntem ile 50. günün sonunda $120 \mathrm{~mm}$ oturma değeri hesaplanmıştır. $\mathrm{Bu}$ yöntem ile hesaplanan zamana bağlı oturmaların ölçüm sonuçlarına uygunluğu iyi olmakla birlikte diğer yöntemlerle kıyaslandığında biraz uzak kalmıştır.

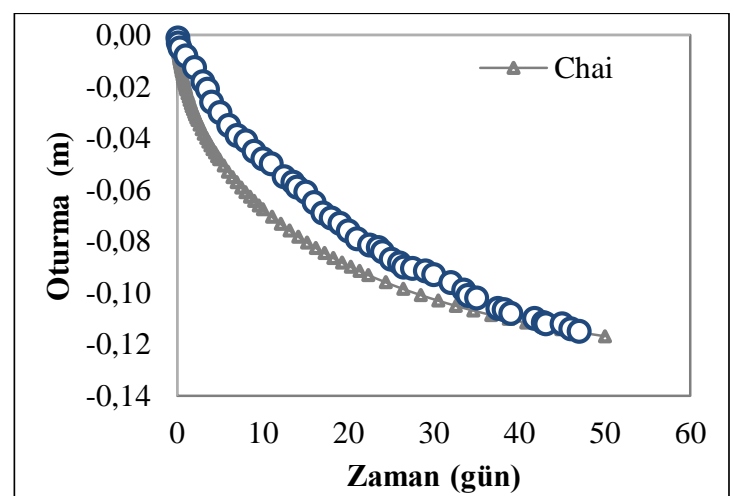

Şekil 10. Chai (basit yöntem) eşleme yöntemi analiz sonuçları

Şekil 11'de ise bu araştırma kapsamında kullanılan tüm eşleme yöntemlerine ait sonuçlar toplu olarak deneysel ölçüm sonuçları ile karşılaştırılmıştır. Tüm eşleme yöntemlerinin deney sonuçları ile uyum içerisinde olduğu fakat ölçüm sonuçlarına göre bir miktar farklılıklar görülmektedir. Bunun nedeni olarak eşleme yöntemlerinde zemin 
davranışının lineer elastik kabul edilmesi gibi bazı basitleştirici kabullerin yapılması gösterilebilir.

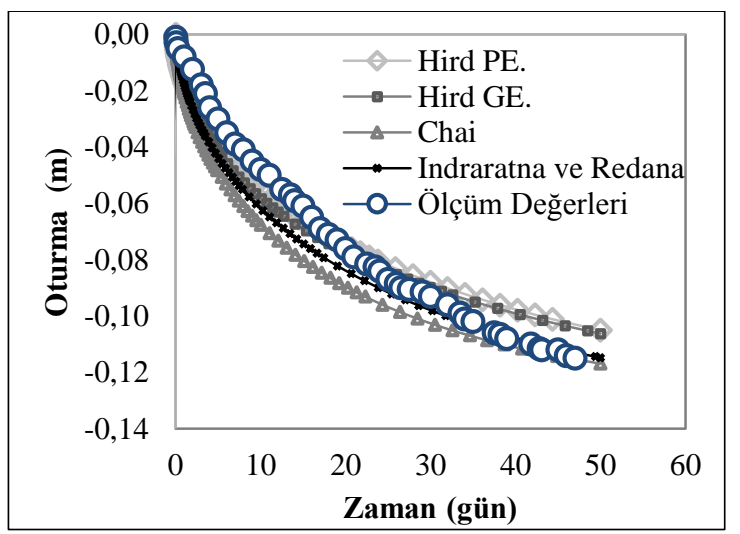

Şekil 11. MCC zemin modelinde yapılan analizlerin sonuçları

\section{SONUÇLAR}

Bu çalışmada, yumuşak kil zeminlerde inşa edilen düşey dren sistemlerinin 2 boyutlu koşullarda düzlem deformasyon koşullara dönüştürülmesi için geliştirilen farklı eşleme yöntemlerinin uygulanabilirliği deneysel ölçüm sonuçları ile karşılaştırılarak araştırılmıştır. Sayısal analizlerde PLAXIS 2D V8.6 programı kullanılmıştır. Düşey drenlerin eksenel simetrik koşullardan düzlem şekil değiştirme koşullarına dönüştürülmesi için Indraratna, Hird ve Chai tarafından geliştirilen 3 farklı yöntem kullanılmıştır. $\mathrm{Bu}$ yöntemlerin doğruluğunu araştırmak için Saowapakpiboon et arkadaşları [4] tarafından laboratuvar koşullarında gerçekleştirilen büyük ölçekli konsolidometre deney sonuçları kullanılmıştır. Elde edilen sonuçlar aşağıda sunulmuştur.

Düşey drenli olarak gerçekleştirilen büyük ölçekli laboratuvar deney sonuçları ile kıyaslandığında üç farklı eşleme yöntemi ile hesaplanan oturmazaman grafikleri ile deney sonuçlarının uyum içerisinde olduğu görülmüştür. Deney sonuçlarına en yakın sonuçları veren eşleme yönteminin Indraratna ve Redana yöntemi olduğu görülmüştür. Chai yönteminde ise diğer 2 eşleme yöntemine göre uyum biraz daha uzak elde edilmiştir. Fakat Chai yönteminin çok daha basit bir yöntem olması, düşey drenlerin modellenmesine gerek olmaması nedeniyle uygulamada tasarımcılar için daha ideal bir yöntemdir. Ayrica bu eşleme yöntemler geliştirilirken zemin davranışı lineer elastik kabul edilmektedir. MCC gibi elasto-plastik zemin modeli kullanıldığında sonuçlara önemli bir etkisinin olmadığı görülmüştür.

\section{KAYNAKLAR}

1. Hird, C.C., Pyrah, I.C., Russell, D., 1992. Finite Element Modeling of Vertical Drains Beneath Embankments on Soft Ground. Géotechnique, 42, 499-511.

2. Indraratna, B., Redana, I.W., 1998. Laboratory Determination of Smear Zone Due to Vertical Drain Installation. J. Geotech. and Geoenvironmental Engineering, 124, 180-184.

3. Chai, J. C., and Miura, N., 1999. Investigation of Factors Affecting Vertical Drain Behavior. J. Geotech. and Geoenviron. Eng., ASCE, 125(3), 216-226.

4. Saowapakpiboon, J., Bergado, D. T., Voottipruex, P., Lam, L. G., Nakakuma, K. 2011. PVD Improvement Combined with Surcharge and Vacuum Preloading Including Simulations. Geotextiles and Geomembranes, 29(1), 74-82.

5. Şengün, E., 2013. Oyuk Genişlemesi Probleminin Sonlu Elemanlar Yöntemi ile İki Boyutlu Sayısal Analizi. İstanbul Teknik Teknik Üniversitesi, Yüksek Lisans Tezi, İstanbul, 85 .

6. Zienkiewicz, O.C., 1977. The Finite-Element Method. $3^{\text {rd }}$ ed., New York, McGraw-Hill Book Co., 787.

7. Brinkgreve R. B. J., 2002. Plaxis Finite Element Code for Soil and Rock Analysis. 2d Version 8.2.

8. Yıldız, A., 2007. Düşey Drenlerin Sayısal Analizi. 2. Geoteknik Sempozyumu, Kasım 2007, Çukurova Üniversitesi, Adana.

9. Asaoka, A., 1978. Observational Procedure of Settlement Prediction. Soils and Foundations, 18(4), 87-101.

10. Plaxis V.8 Material Models Manual, 2008.

11. Das, B.M., 1995. Advanced Soil Mechanics. Mc. Graw-Hill Book Company, New York, U.S.A, 567. 
12. Keskin, M.S., 2009. Güçlendirilmiş Kumlu Şevlere Oturan Yüzeysel Temellerin Deneysel ve Teorik Analizi. Çukurova Üniversitesi, Doktora Tezi, Adana, 377.

13. Brinkgreve, R.B.J., Broere, W., Waterman, D., 2006. Plaxis, Finite Element Code for Soil and Rock Analyses. Users Manual. The Netherlands.

14. Durmuş, C., 2019. Taş Kolonlar ile İyileştirilen Yumuşak Killerin Deformasyon ve Göçme Davranışı. İstanbul Üniversitesi, Yüksek Lisans Tezi, İstanbul, 166.

15. Brinkgreve, R.B.J., Broere, W., Waterman, D., 2011. Plaxis 2D- 2011 Material Models Manual. Delft University of Technology \& PLAXIS b.v., The Netherlands. 